QUARENTA ANOS DEPOIS 


\section{Quarenta Anos Depois Homenagem Aos Editores Da Revista Letras}

Realizamos uma pesquisa na coleção dos quarenta números da Revista Letras a fim de estabelecer a cronologia e a identidade dos professores responsáveis pelas sucessivas edições do periódico ao longo dos anos. De posse das informações, enviamos correspondência aos ex-editores para recolher depoimentos que pudessem registrar a história da revista. Recebemos em troca valiosas contribuiçōes que publicamos na integra neste número, acompanhadas da lista contendo o nome dos editores, periodo e números anuais sob sua responsabilidade.

Os depoimentos reproduzidos abrangem a origem e a continuidade da revista, as primeiras intençōes, as dificuldades financeiras e o questionamento de sua função cultural. Retratam um pouco da trajetória constante, porém difícil, da Revista Letras nas últimas quatro décadas.

Tencionamos com esta iniciativa homenagear aqueles professores que, além das habituais tarefas de docência e pesquisa, dedicaram abnegadamente parcela representativa de seu tempo para manter um periódico dedicado exclusivamente à arte è̀ cultura.

A eles nosso reconhecido agradecimento e singela homenagem.

O EDITOR 


\section{Depoimento do Prof Dr. Reinaldo Bossmann}

Em 1952, os professores do Curso de Letras da antiga Faculdade de Filosofia, Ciências e Letras - então distribuidos entre os Departamentos de .Letras Clássicas, de Neolatinas e de Anglo-Germânicas -passaram a reunirse quase mensalmente, com a participação de estudantes, para assistirem conferências de professores estrangeiros e da própria casa. Os temas foram diferentes, com conteúdo atual e histórico. Assim, foi criado em 1953, o Centro de Estudos Lingüisticos do Paraná. Nesse Círculo surgiu a idéia de publicação de uma revista anual com o título Letras, que comemora atualmente $\mathbf{4 0}$ anos de existência, data significativa e de júbilo para as gerações de mestres. O primeiro número da revista saiu no ano de 1953 com o apoio do então diretor da Faculdade, Prof. Dr. Homero Batista de Barros, que providenciou a verba necessária para a realização do plano. Ele escreveu o prefácio do $1^{9}$ número e destacou entre outros itens os seguintes: "Dada a universalidade desta instituição, serão aqui acolhidos os artigos, das respectivas cadeiras, em língua estrangeira. Mas a revista destina-se também à guarda do idioma nacional, como instrumento mantenedor de nossas tradições. Nisso repousa uma das duas finalidades precípuas, ainda porque 'a inteireza do espirito começa por se caracterizar no escrúpulo da linguagem'. "E continua: "A ofensiva que, nos últimos tempos, se desencadeou contra as instituições tradicionais de nacionalidade, com desmascarado propósito de aniquilá-la, quer através de atentados à familia e aos valores do organismo social, quer contra o que há de mais venerável na Pátria, que é a Religião, não poupou, na sanha destruidora, estoutro precioso elemento da sociedade -a língua, que lhe reflete a história, a indole, as tendências, os costumes, a alma nacional."

Assim, o precursor da Revista Letras foi o Centro de Estudos Lingüisticos do Paraná.

Regularmente, quase todos os mestres do Curso de Letras assistiram às reuniões. Muitos dos colegas já são falecidos, como o eminente prof. Rosário Farani Guérios, o prof. Oswaldo Pinheiro dos Reis e o catedrático Dr. Luigi Castagnola; outros são eméritos e aposentados. 
Desejamos à Revista Letras uma continuação secular, para que os futuros mestres desenvolvam trabalhos importantes, seguindo os caminhos de seus colegas fundadores, que se dedicaram à vida universitária, com orgulho e amor, apesar da remuneração modesta, no sentido do progresso do Pais e da ciência imortal.

Prof. Dr. Reinaldo Bossmann Catedrático de Língua e Literatura Alemã Professor Emérito 


\section{Depoimento do Prof. Oswaldo de Oliveira Portella}

"EXEGI MONUMENTUM AERE PERENNIUS" (Horicio, Ode XXX)

Imbuído desse sentimento, Dr $\mathrm{r}^{\mathrm{a}}$ Marta, agradeço-lhe a lembrança de solicitar meu depoimento a respeito dos 40 anos da Revista Letras, tão querida de todos nós.

Devo inicialmente declarar que me sinto deveras orgulhoso de ter contribuído, mesmo que modestamente, na edição de quatro números de nossa Revista Letras. Hoje sei, como aliás já sabia, que trazer à luz uma revista científico-literária aqui no Brasil, por tanto tempo, é mais que um trabalho de Hércules. Não tanto pela falta de colaboradores mas, muito especialmente, pelas dificuldades financeiras que tal feito acarreta. Ao contrário, aos colegas devo agradecer a colaboração nunca negada. A falta de verba, entretanto, foi angustiosa. Nunca se sabia se o próximo número seria possível. Dependeu sempre de sobras do orçamento da Universidade. Nas fases de maior carência, foi-nos sugerido suspender por um ano ou, ao menos, que utilizássemos material inferior (papel-jornal, por exemplo) para baratear o custo.

Em 1984, para efeito de diminuição de custos, confiamos a edição do $n^{2} 33$ à gráfica da Fundação da Universidade Federal do Paraná. Não posso afirmar que essa edição foi mais econômica. A vantagem pode ter sido o dinheiro não precisar sair da Universidade.

De resto, creio devermos um grande protesto de agradecimento à Gráfica Vicentina Ltda. por seu trabalho correto, pontual e dentro dos menores orçamentos, o que possibilitou a vida de nossa Revista Letras até os dias de hoje.

Nos quatro números sob minha direção $(32,33,34,35)$, dentre tantos ótimos e assíduos colaboradores, destaco a contribuição do sempre lembrado e querido prof. Mansur Guérios que, com seu renome nacional e internacional, deu o suporte de credibilidade cientifica de que uma revista deste gênero jamais pode prescindir. Devo destacar ainda que foi na Revista 
Letras que muitos professores, colegas nossos, com absoluta prioridade, encontraram o espaço adequado à publicação de suas pesquisas, podendo assim crescer literária e profissionalmente em proveito da educação e da cultura de nosso povo.

A par de meus agradecimentos, $\mathrm{Dr}^{3}$ Marta, desejo que a Revista Letras, sob sua direção não obstante lutas e canseiras, continue "ad multos annos" sua caminhada gloriosa de revista cientifico-literária mais antiga da mais antiga Universidade do Brasil.

Curitiba, 2 de junho de 1993

Prof. Oswaldo de Oliveira Portella 


\section{Depoimento do Prof. Dr. Édison José da Costa}

Fui designado editor de Letras no ano de 1987. Tive assim a oportunidade de conduzir a edição do exemplar 36, referente àquele ano. Encerrado, todavia, o processo de produção com a entrega da revista à Seção de Intercâmbio da Biblioteca Central, para a remessa aos assinantes, apresentei à direção do SCHLA meu pedido de afastamento. Havia sido eleito para a coordenação do Curso de Pós-Graduação em Letras e acreditava, como acontece até hoje, que ao se evitar que um mesmo professor acumule funções se abre caminho para que maior número de docentes se integre produtivamente ao centro de condução da vida universitária, expandindo-o saudavelmente.

Diferentemente dos exemplares que a precederam, Letras/36 deixou de abrigar textos de criação, destinando-se à veiculação exclusiva de ensaios críticos organizados em dois conjuntos espacialmente distinguidos: Estudos Lingüísticos e Estudos Literários. Para cada um das áreas assim estabelecidas destinou-se um coordenador, retirado de entre os integrantes do conselho editorial.

Os ensaios críticos, compostos em português, francês, italiano, inglês ou alemão - línguas integrantes do currículo do Curso de Letras da UFPR, passaram a trazer resumo introdutório redigido $\mathrm{em}$ língua portuguesa, entendendo-se que a brasileiros, principalmente, deve procurar dirigir-se a produção científica nacional.

Mas para quem realmente escreve o professor universitário curitibano cujos trabalhos costumam sair em Letras? Não será exagero supor que apenas os pares, professores locais ou de outros centros, constituam o eventual público leitor do ensaio de lingüistica ou literatura veiculado pela revista. Compor ensaios e artigos científicos, então, para quê? Como um ato de resistência, acredito, pois é em face do quadro cultural mais amplo que incentiva a transferência, a repetição e a subalternidade que se dimensiona mais apropriadamente o enclausuramento e a desvitalização da vida universitária. Estão aí visíveis, palpáveis o desmantelar contínuo da escola pública, o desmoronamento de todo um sistema educacional. 
Seria impróprio, de qualquer forma, tentar reduzir o problema a aspectos restritos e elementares. $O$ todo é naturalmente complexo. Produz-se muito texto de menor valor, certamente, tornando o quadro que se discute ambiguamente multifacetado. Mas quantos moços loiros foram necessários antes de se chegar a um dom casmurro, quantos sertanejos precisaram soltar a voz antes de Riobaldo?

\author{
Junho de 1993. \\ Édison José da Costa
}




\section{Depoimento do Prof. João Alfredo Dal Bello}

Contar a história da Revista Letras é também revisitar caminho andando por alguns teimosos. Ao menos essa foi a marca do nosso trajeto entre 1988 e 1990, quando em grandes dores foram paridos os números 37 , 38 e 39.

Essa pertinácia estava ligada intimamente à convicção de que nossa revista tinha razão de ser por sua história pregressa (consta-me ser a mais antiga do gênero, no país) e pela insistente procura tanto da parte de colaboradores como de leitores aqui e fora do Brasil. Este era o aspecto alentador do trabalho; o reverso ficava por conta da crônica falta de recursos. A cada novo número um outro enfrentamento de ordem financeira. Se chegávamos ao montante exigido pelas gráficas, certamente faltaria numerário para a franquia postal.

Foi nessa quadra que deixamos de contar com apoio financeiro do Setor de Ciências Humanas, Letras e Artes. Então os dois departamentos do Curso de Letras - Lingüística, Letras Clássicas e Vernáculas e Letras Estrangeiras Modernas - passaram a destinar parte de seus minguados recursos para Letras.

Em 1987, a Revista Letras passou por uma transformação que ainda se mantém. Dividiu-se em duas áreas: estudos lingüísticos e estudos literários, e excluiu de suas páginas a publicação de textos literários, limitando-se a estudos críticos. Reuniu para o número 37 trabalhos agrupados ao tema sugerido: Literatura e História. No número 38 (1989), para encerrar a década, os colaboradores trataram temas ligados à literatura dos anos oitenta e outros que refletiram a trajetória lingüística mais recente.

O último número sob nossa responsabilidade, 39 (1990), surgiu com novas caracteristicas editoriais e gráficas e foi publicado pela Editora da UFPR, inaugurando nova marca da política editorial da instituição.

É muito prazeroso voltar os olhos para constatar que Letras vai fazendo seu caminho enquanto avança a despeito de tantos percalços. Um brinde à Revista Letras por suas quatro décadas e a todos os teimosos que a trouxeram atć aqui e, certamente, vão levá-la a ver outras muitas. 


\section{Editores Da Revista Letras}

\begin{tabular}{|c|c|c|}
\hline Número & Data & Editor \\
\hline 01 & 1953 & $\begin{array}{l}\text { Comissão de Redação } \\
\text { Temístocles Linhares } \\
\text { Rosário F. Mansur Guérios } \\
\text { Guillermo de la Cruz Coronado }\end{array}$ \\
\hline 02 & 1954 & Rosário F.M.Guérios e Guillermo C. Coronado \\
\hline 03 & abr. 1955 & Mansur Guérios e Coronado \\
\hline 04 & set.1955 & Mansur Guérios e Coronado \\
\hline $05 / 06$ & 1956 & Mansur Guérios e Coronado \\
\hline $07 / 08$ & 1957 & Mansur Guérios e Coronado \\
\hline 09 & 1958 & Mansur Guérios e Coronado \\
\hline 10 & 1959 & Mansur Guérios e Coronado \\
\hline 11 & 1960 & Rosário F. Mansur Guérios \\
\hline 12 & 1961 & Mansur Guérios \\
\hline 13 & 1964 & Osvaldo Ams e Guillermo Coronado \\
\hline 14 & 1965 & Osvaldo Ams e Guillermo Coronado \\
\hline 15 & 1966 & Osvaldo Ams e Guillermo Coronado \\
\hline 16 & 1968 & Osvaldo Ams \\
\hline 17 & 1969 & Osvaldo Ams \\
\hline 18 & 1970 & Osvaldo Ams \\
\hline 19 & 1971 & Osvaldo Ams \\
\hline 20 & 1972 & Temístocles Linhares \\
\hline $21 / 22$ & $1973 / 1974$ & Temistocles Linhares \\
\hline 23 & 1975 & Cecília Teixeira Oliveira Zokner \\
\hline 24 & 1975 & Cecilia Teixeira Oliveira Zokner \\
\hline 25 & 1976 & Cecilia Teixcira Oliveira Zokner \\
\hline 26 & 1977 & Rosário F. Mansur Guérios \\
\hline 27 & 1978 & Reinaldo Bossmann \\
\hline 28 & 1979 & Reinaldo Bossmann \\
\hline 29 & 1980 & Miguelina Soifer \\
\hline 30 & 1981 & Miguelina Soifer \\
\hline 31 & 1982 & Miguelina Soifer \\
\hline 32 & 1983 & Oswaldo De Oliveria Portella \\
\hline 33 & 1984 & Oswaldo De Oliveira Portella \\
\hline 34 & 1985 & Oswaldo De Oliveira Portella \\
\hline 35 & 1986 & Oswaldo De Oliveira Portella \\
\hline 36 & 1987 & Édison José da Costa \\
\hline 37 & 1988 & Joāo Alfredo Dal Bello \\
\hline 38 & 1989 & João Alfredo Dal Bello \\
\hline 39 & 1990 & João Alfredo Dal Bello \\
\hline 40 & 1991 & Marta Morais da Costa \\
\hline
\end{tabular}




\section{O Círculo De Estudos Lingüísticos De Curitiba - Uma Breve Nota Sobre Um Movimento Pioneiro.}

José Borges Neto - UFPR

No ano em que se comemoram os quarenta anos da revista LETRAS não poderíamos deixar de registrar os quarenta anos do surgimento do Círculo de Estudos Lingüísticos de Curitiba, entidade de vida curta e funcionamento irregular que, juntamente com a revista, testemunha a efervescência do pensamento lingüistico na Universidade do Paraná na década de cinqüenta.

\section{A fundação do Círculo.}

Em 31 de outubro de 1953, realizou-se a reunião de fundação do Círculo de Estudos Lingüísticos. Havia doze pessoas presentes a esta primeira reunião: sete professores da Faculdade de Filosofia, Ciências e Letras da Universidade do Paraná (Oswaldo Pinheiro dos Reis, Reinhold Bossmann, Osvaldo Arns, Guillermo de la Cruz Coronado, Irmão Claro, Aryon Dall'Igna Rodrigues, Ladzislau Zawadzki); quatro estudantes (Edda Arzua, Ady Campollin, Serafina Borges do Amaral e Eloyr Blauck) e um convidado especial, o Prof. Francisco da Silveira Bueno, da USP.

A reunião foi presidida pelo Prof. Pinheiro dos Reis e secretariada por Serafina Borges do Amaral. A pauta da reunião foi integralmente ocupada por questões organizacionais, tendo ficado decidido que a finalidade do Círculo seria "o intercâmbio de idéias sobre lingüistica em 
geral, gramática, português, etc."; ${ }^{1}$ e que haveria o pagamento de uma pequena quantia em dinheiro pelos associados para a assinatura de revistas especializadas. Ficou decidido também que os alunos de Letras da Universidade do Paraná seriam convidados a participar.

Estabeleceu-se também, nesta primeira reuniāo, a dinâmica do Círculo: a cada sessāo um associado - ou um convidado - apresentaria uma tese. Os presentes tomaram, ainda, uma decisão que poderia ter sido decisiva para a curta existência do Círculo: decidiu-se que o Círculo funcionaria "sem as formalidades de praxe, isto é, eleiçāo de presidentes, secretários, etc. o que viria sempre a dar um certo cunho político ao Centro [sic], o que é sempre desagradável." Aprovou-se que "o Presidente será associado que tiver tese a apresentar durante uma sessão, e só por aquela sessão - isto $\dot{c}$ o Presidente só o será por uma sessão."

\section{O funcionamento do Círculo.}

O Círculo realizou 14 sessōes, entre outubro de 1953 e novembro de 1955, quatro das quais ainda no ano de 1953.

A segunda reuniāo do Círculo deu-se em 03 de novembro de 1953 e contou com 16 presentes, além do palestrante, Prof. Kurt Herbert Halbach, da Universidade de Tübingen, que falou "sobre seus estudos e pesquisas sobre a literatura cavalheiresca". 4 A terceira reunião ocorreu em 14 de novembro de 1953, contou com 11 presentes e consistiu numa palestra do Prof. Reinhold Bossmann sobre a Lei de Grimm. A quarta reunião realizouse em 12 de dezembro de 1953 e consistiu numa palestra do Prof. Aryon Dall Igna Rodrigues sobre "Terminologia Fonética" para os 8 presentes.

No ano de 1954, o Círculo reuniu-se sete vezes, sendo a primeira em 03 de abril e a última em 18 de setembro. Em 1955, realizaram-se mais três reuniōes (em 15/10,22/10 e 5/11), que foram as últimas. O número médio de participantes dessas reuniōes foi de 23 , sendo que a sessāo de 22 de outubro de 1955 chegou a contar com 40 presentes (a média geral do número de participantes do Cúrculo nas 14 reuniōes é de dezessete).

Ata da primeira rauniāo do Circulo de Estudos Lingüisticos - 31/10/53.

Ata da primeira reanião do Circulo de Estudos Lingüisticos - 31/10/53.

Ata da primeira reunião do Círculo de Esudos Lingüisticos - 31/10/53.

Ata da segunda reuniāo do Círculo de Estudos Lingüisticos - 03/11/53. 


\section{Os assuntos tratados pelo Círculo.}

Com relação aos assuntos tratados nas 14 reuniões do Círculo, pode-se dizer que o Círculo não fazia justiça à lingüistica que se praticava à época nas universidades européias e norte-americanas. A grande maioria das sessões tratou de assuntos ligados à Filosofia e à Lingüistica HistóricoComparativa.

As discussões mais interessantes, no entanto, não estão nas reuniōes de apresentação de "teses", mas estão nas quatro reuniōes em que se trataram de assuntos "organizacionais".

$\mathrm{Na}$ reunião de 15 de maio de 1954, por exemplo, discutiu-se a possibilidade de criação de uma "Secção de Pesquisas [sic] Lingüísticas", ligada ao Instituto de Pesquisas da Faculdade de Filosofia da Universidade do Paraná, dirigido, então pelo Prof. José Loureiro Fernandes. Não só a criação é aprovada como é aclamado pelos presentes, como Diretor dessa nova "Secção", o Prof. Rosário Farâni Mansur Guérios. Essa decisão deixa claro o caráter acadêmico que começava a ser imprimido aos estudos lingüisticos na Universidade do Paraná, e ao Círculo, ultrapassando-se o caráter de "sarau" que o relato de algumas das sessões deixava transparecer.

$\mathrm{Na}$ reunião de 5 de junho de 1954, discute-se a proposta de um estreitamento de relaçōes entre o Círculo e os professores de português dos cursos ginasiais e colegiais. Embora de forma ainda canhestra, a interrelação entre os vários niveis do ensino começava a ser formulada. Creio ser interessante transcrever aqui um trecho da ata da sessão.

... o Prof. Pinheiro dos Reis apresenta dois artigos aparecidos no "O Estado do Paraná" em que se faz referências ao Círculo de Estudos, um do dia 27 e outro do dia 29 de maio, e que são de autoria de um antigo aluno do Colégio Si Maria. Seria interessante que o Círculo se aproveitasse dessa publicidade para procurar o interesse dos professores de português, tanto dos cursos ginasiais como dos colegiais, para que entrem para o Círculo. Pede o professor [o professor articulista, presumo. JBN] que lhe seja enviada uma nota com informaçōes sobre as conferências programadas, assunto, e conferencista, para que lhe seja possivel mandá-la publicar em "O Dia" e o "Estado do Paraná". Pedir aos professores referências sobre bibliografia, deixá-las com a Secretária do Círculo, para consultas dos interessados. $^{5}$ 


\section{A importância do Círculo.}

Creio que caberia dizer aqui que a importancia cientifica ou acadêmica das atividades do Círculo de Estudos Lingüisticos é praticamente nenhuma. O Círculo é importante na medida em que é uma das primeiras tentativas de organizaçāo da comunidade dos lingüistas, organização que só se vai conseguir, parcialmente, alguns anos depois com a criação da Associaçāo Brasileira de Lingüistica (ABRALIN), que não por acaso tem como seu primeiro presidente o Prof. Aryon Rodrigues, um dos fundadores do Círculo de Curitiba.

Para encerrar, gostaria de deixar aqui minha homenagem a SERAFINA BORGES DO AMARAL, secretária do Círculo desde a primeira reunião, pois, se não fosse a extrema clareza de suas atas, que descrevem circunstanciadamente as discussōes ocorridas nas sessōes do Círculo, não poderia, hoje, ter escrito esse pequeno texto que, com suas muitas limitações, busca lançar algumas luzes na história dos estudos lingüísticos no Brasil.

Curitiba, junho de 1993. 


\section{UNIVERSIDADE DO PARANA:}

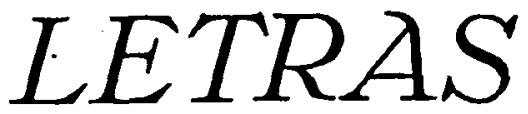

DEVISTA DOS CURSOS DE LETRASS CLASSICAS, NEOLATINAS E ANGLOGERMANICAS DA FACULDADE DE FILOSOFLA, CIENCLAS E LETRAS DA URIVERSDADE DO PARANÁ.

$$
\begin{gathered}
\text { N.e } 1 \\
\text { - CURITIBA - }
\end{gathered}
$$




\section{A MAGIA DA PALAVRA}

\section{R. F. MANSUR GUERIOS Universidade do Paraná}

Maravilha da Criação, a palavra é uma das mais singulares e extraordinárias dádivas com que Deus, o Verbo, brindou o homem, exalçando neste a semelhança com Ele ("Façamos o homem à nossa imagem e semelhança" - Gen., I, 26), facultando-lhe também criar o mundo do nada, como o fêz nos primórdios mediante os miraculosos Fiat...!

Falar é pensar; falar é corporificar o espírito; falar é concretizar o pensamento; falar é criar; falar é dominar; falar é viver!

Assim, não é para admiração haja o homem, em todos os quadrantes da Terra, votado à palavra singular respeito ou então inquietante pavor, principalmente nas manifestaçöes religiosas, porque ela demonstra a vontade do Ser ou de sêres sobrenaturais, a que as criaturas devem sujeita obediência.

As Sagradas Fscrituras estão cheias de vida e maravilhas manifestadas pelas palavras divinas ou dos profetas. $E$ muito expressivo é o que se testemunha em S. Lucas (IV-33-35). Relacionaram os circunstantes, perplexos, o ato de Jesus, que desendemoninhou uma vitima, com os prodígios que atribuíam à palavra, em certas circunstâncias, independente, parece, da Divindade que a proferiu. Assim, os atônitos: - "Quod est hoc verbum, quia in potestate et virtute imperat immundis spiritibus, et exeunt?" (S. Lucas, IV-36). - "Quod est hoc verbum?..."

Com a palavra dirige-se o homem à Divindade ou aos deuses. Pede-se, suplica-se, agradece-se!

Com a palavra abençoa-se, amaldiçoa-se, satiriza-se, pragueja-se! 
Com a palavra dominam-se as tớrças ocultas ou assenhoreiam-se delas!

Com a palavra curam-se as doenças, desfazem-se os malefícios e as pragas!

Com a palavra sagram-se as coisas e evitam-se as profanas!

Com a palavra respeitam-se, veneram-se, divinizam-se homens, cidades e coisas!

Com a palavra predizem-se as fatos vindouros!

Com a palavia perdem-se ou deparam-se as coisas!

Com a palavra tem-se o mundo nas mãos! (1)

Vejamos agora perfuntòriamente alguns exemplares dessas palavras ou frases ou rezas não pròpriamente religiosas, porém supersticiosas.

Visto que usos e costumes e instituiçōes criam necessàriamente uma terminologia pela qual se pode fazer uma idéia claIa da vida de um povo, lancemos a vista para a nomenclatura da vida religiosa, p. ex., dos romanos, através das suas manifestaçōes orais. E de qualquer modo um espelho das crenças símiles dos demais poros:

Invocare, evocare, invocatio, praefari, profari, effari (templum), fatum, fas (2), fastus, nefas, nefarius, nefandus, infas, infandum, orare, oraculum (3), adorare, dicere, benedicere (4), maledicere, dicare, dedicare (5), nuntiare, praenuntiare, etc.

As oraçỏes, fórmulas mágicas, ensalmos, encantamentos, etc., através de todos os tempos, entre os povos das mais diversas latitudes, podem manifestar-se com longas palavras ou

( 1) DYz-se de Amon Ra: "Sus palarra é uma subshock...) (Moret, "Mystères Ifyptiens", Paris, 1922 (citado por ML Jousse).

( 2) Opóe-se a fas, "direlto humano". Fas personlficou-se e divinizou-se.

(3) Primlturmente: "lugar onde se faz pedido (a delus)". Ver A. Brnout e A. Melliet, "Dlctionnalre E'tymologique de la Langue Iatine", Parls, 1951.

(4) Primituamente: "pronunctar palarras de bom augúrio", como o segulate the é o antorimo (Exnout e Meillet, DEL).

( 5) "Consagrar aos deuses em termos solenes" (Id, ib.) 
mesma com uma única, e podem obedecer a requisitos ou exigências formais, externas, variadíssimas.

Entre os muçulmanos, pronunciar esta singela palavra agla - voltado para o Oriente, possibilitava conhecer o futura ou achar os objetos perdidos (6).

As vêzes, são mais eficazes as expressões gráficas (7). "Tam. bém é conhecida, afirma $O$. Jespersen, a grande importância mágica que em algumas partes se concede a palavras ou letras pintadas ou escritas de diferentés maneiras sôbre diferentes objetos, as quais dão a quem traça, poder sôbre pessoas ou coisas".

A propósito, lembremos que os caracteres escritos, entre 08 povos primitivos, foram considerados mágicos, sagrados, de origem divina.

Não é sem motivo que as figuras, os desenhos do antigo Egito hajam sido denominados hieroglyphikà grámmata pelos Gregos (8).

As runas, caracteres da escritura dos povos nórdicos, eram provdvelmente, assim chamadas pelo fato de que êsses poros

(6) Numa tórmula de evocapso aos espiritos, entre nomes gregos e hebralcos da Divindedo, depera-se com Aglisl tress veres em regulds (J. W. Scott, "Tratado de Magia Oculta", 8. Paulo, 1945, p. 40). Mas deve ser orro gráfico, porquanto nums oragho "contra majartcios diabblicos" (J. Laite de Vasconcelos, "Opúsculos", V, p. 542), Iniclada 18ualmento com nomes eqtrangetro de Deus, ha agle ("sic") e agyos ("slc") que nada mals sáo do que o grego háglos, -is, lon, "santo".

(7) "Se comprende por al mismo que el fetichlarno de la palabra no pudo más que ser alentado con el descubrimiento de la escritura, pues un follo of un escrito perfectamente claro a slempre mucho mis abarcable que un allento fugaz. Por esto el amuleto, un trozo de papel en. una capsula, es un extendidisimo medio mágico, especlaimente en lon palses del Islam". (F. Msuthner, "Contribulclones uns Critloa del Lenguaje", trad., Madri, 1921, p. 269).

( 8) A. Hrian, "Dle Hieroglyphen", Berlim e Lípsis, 1932, p. 1. No entretanto, ha quem o expllque por escrita "ininteligivel", misterloss ou emblemsitica, em vista de os hleroglificos, durante séculos, desaflarem todas as tentativas de decifrá-los ("Everyman'e Encyclopaedia", 3". ed., 1951, s.v. hieroglyphic). Antenor Nascentes ("Dic. Etim. da L. Port.", I) explica ou interpreta - "gravura felta pelos sacerdotes "egipclos)", quando, na verdade, tal é reservado ao termo hierticico. 
lhes atribuiam poderes mágicos, misteriosos (9). Tal nome (nordico antigo ran) significava "mistério, segrêdo" (10). Portrn, assevera $O$. Jespersen que "las runas fueron al principio más bien ensalmos que medios de comunicación". E cita entre outras: "Aprende runas de falar para que ninglém trate de responder a ofensa com ódio".

"Aprende runas de pensar, assim todos creräo que és o mais agudo dos homens" (11).

Lembraremos, ainda, que se atribuía a Odin, divindade escandinávica, a invençāo das runas, da poesia e da magia.

A respeito da "escritura" pascoense, ouçamos o que diz J. Imbelloni (12): "Los habitantes de Pascua que vivieron en la época brillante $y$ constructiva de la isla tributaron a esos signos el mismo religloso respeto que en todo otro lugar acompana a los vestigios de antiguas grafías, y todo lo que se nos ha transmitido sobre ello comprueba que una suerte de poder mágico se derramaba por su medio sobre la casta sacerdotal y la realeza".

Atribuíam-se à voz abracadabra - expulsão dos espíritos maus e curas de doenças. Seus efeitos, contudo, manifestavam-se com as letras postadas em triângulo, de tal jeito que se podia ler essa palevra em todos os sentidos:

( 9) "Everyman's Encyclopredla". 3.v. ranen

(10) W. W. Skeat, "A Oanclse Etymological Dhet. of the Eaglish Language", Oxforde, 1024; E. Wasserzleher, "Woher? - Ablelt. Worterb. der deut. Bprache", Berlum e Bons, 9." ed.. 1935: Eluge - Gotze, "Etym. worterb. der deut. Sprache", Berlim, 15." ed., 1851.

(11) "Humanidad, Necló, Individuo", trad., B. Aire6, 1947, p. 219-220.

(12) "Las 'Tabletas Parlantes' de Pascua" in "Runa". v. IV. B. Aires, 1951, p. 160 . 


\section{ABRACADABRA \\ ABRACADABR \\ ABRACADAB \\ ABRACADA \\ ABRACAD \\ ABRACA \\ ABRAC \\ ABRA \\ ABR \\ $A B$}

A

Há outra disposiçăo mágica (13):

A B A C A D A B A R A
B A C A D A B A R
A C A D A B A
C A D A B
A D A
D

Como amuleto, era escrito em objeto que se atava ao pescoço. Por náo nos interessarem, deixamos de lado outros usos supersticiosos do escrito abracadabra.

Segundo Bloch, citado por Augusto Magne (14), êśse nome provém, "de um modo obscuro", de abraxas, abrásax (15) - "palavra cabalística grega, muito freqüente em pedras que serviam de amuletos a adeptos do gnóstico Basilides, séc. II", pois assim chamavam a Divindade e que, no entanto, segundo S. Jerônimo e outros, era o nome místico de Mitra.

(13) Brewtan Berry, "Voct e Buss Superstiçoes", trad., 8. Paulo, 1945, p. 204. Comparando-se a palavra máfica desta obra com outra, de malar difusio, Inclinamo-nos a ver aqui uma deturpaça; hs falta de um r e acréscimo de un a.

(14) "Dicionário Etimológlco da Língus Portuguess", I, Rlo, 1950, s.v. abraxas.

(15) Além destas formas, ha alnda abraeax (v. "Dic. E Encicl. Intern."). E posarfel que todan tenham sido deformaçes voluntárias de um só nome, em obediencla também a disposiç̧o vartável nas letres pars os efeltos desejados, embora noo escritas. Cp. wbraxas = abre-as-an; abraanx = abra-as-cs; abracax = abra-ca-om. 
Ha outras fórmulas escritas que também costumam aparecer com as letras em ordem a possibilitar a leitura por qualquer lodo:

$\begin{array}{lllll}\mathbf{S} & \mathbf{A} & \mathbf{T} & \mathbf{O} & \mathbf{R} \\ \mathbf{A} & \mathbf{R} & \mathbf{E} & \mathbf{P} & \mathrm{O} \\ \mathbf{T} & \mathbf{E} & \mathbf{N} & \mathbf{E} & \mathbf{T} \\ \mathbf{O} & \mathbf{P} & \mathbf{E} & \mathbf{R} & \mathbf{A} \\ \mathbf{R} & \mathrm{O} & \mathbf{T} & \mathbf{A} & \mathbf{S}\end{array}$

Tal se acha, p. ex., num manuscrito do séc. XVII, da Biblioteca Nacional de Lisbor. Consta que é eficaz contra bruxedos, quando recitada à direita e às avessas. Em outros países há essas e outras virtudes com variadas exigências: Em regiões da Suíça, proferida cinco vêzes, desaparecem as dores de dente; pronunciada e escrita, protege-se o indivíduo contra ladrōes (11).

Há diferentes interpretaçóes. Acolhe Artur Resende no seu dicionário uma explicação jocosa - "emblema da diligência e preguiça": "Sator (o agricultor) tenet opera (cuida da lavoura); a[d]repo rotas (e eu passeio de carro)" (16).

No entanto, J. Leite de Vasconcelos (17) diz que lhe parece definitiva a seguinte - Sat orare potenter et operare ratio tua sit - que, afinal, não passa de paráfrase ao lema de origem monacal - Ora et labora!

Simile é esta fórmula que o mesmo L. de Vasconcelos inse re no v. V dos "Opúsculos", p. 545. Diz-se que foi composta pelo demônio, e pode ser lida com as letras às avessas:

Sigma to signa te, me tangis of angis

Rome tibi subito, motibus ibit amor.

Há, contudo, fórmulas e oraçōes que năo se lhes descobre o sentido. P. ex., para esquecer alguém, entre várias exigências, lançam-se em rio ou lago três flores, dizendo, em voz baixa, ao atirar a primeira: On Alan Apell Sar Jani Sem; ao lançar a segunda: On Uquir, Sitrofmo Sem; e, por fim, Uetle Nsip Jego Mal: Ave Anox Otson Naroe Jam Sem (18).

(18) "Irreces e Curlosidedes Latines", 94 ed., RJo, 1936, p. 708.

(17) "Opasculos", V, p. $\$ 4$ e 548.

(18) J. W. Bcott. "Tratedo de Magla Oculta", p. 68. 
Na Ilha Terceira, Açôres, há uma reza, entremeada de persịgnaçס̄es, para desenfeltiçar, constante destas misteriosas expressōes: Corunguena + santa cruz + mechiconto + jéque + demenada + domenatatada + subistisanto (19).

Pode ser que haja propósito no uso de vocábulos inventados, forjados ou deformados, os quais ficam sendo estoglossias (20). Mas anote-se que o filósofo grego Jâmblico, nos seus "Mis. térios Egípcios" (De Mysteriis), em que considerava de grande relêvo os mistérios, e, pelos ritos secretos, o homem podia relacionar-se com a divindade, recomendava que, nas fórmulas mágicas, não se empregassem têrmos vernáculos, mas bárbaros, que tais eram "revelados" pelos deuses (21). Como exemplo, sirva a frase etrusca arseverse, que se escrevia nas portas das casas romanas, equivalente à latina averte ignem! "afasta o fogo!" (ou talvez averte, ignis!). Era preservativo contra incêndio. Ver Leite de Vasconcelos ("Opúsculo", V, p. 553), o qual diz: "O uso de letras e palavras, principalmente em lingua desconhecida, para revelarem mais mistério, é igualmente muito antigo". Registra essa locução o "Dic. Lat.-Port." de Saraiva Será que a frase equivalente latina é a tradução da etrusca? Ou se trata de "etimologia popular": arse lembraria as formas do pretérito de ardere e verse coincidiria fortuitamente com avértere? De qualquer mado, não deixa de ser uma imprecação.

Há inscrições mágicas da Gália, em que se misturam expressões gaulesas, gregas e latinas (22). Pode ser que tais misturas sejam propositadas, assim como propositados os expedientes de outras fórmulas. O mesmo A. cita outra inscriçāo mágica dos gauleses num alfabeto intermediário entre o grego e o etrusco, e apenas uma palavra apresenta aspecto céltico. E há outras que, embora mostrando alguns vocábulos latinos, os

(19) L. B. Rlbelro, "Notas de Etnografia da the Tercelra" in "Rev. Irud$\operatorname{tans} ", 32,1834$, p. 253.

(20) A respelto de expressbes destituidas de argalficado, 7 . Rodolfo Becot "Ises Estoglosies", Madri, 1911.

(21) A. Camoy, "La Bclence du Mot", Lovalns, 1927, p. 880.

(22) G. Dottin, "La Langue Gaulolse", Paris, 1920, p. 49 e 43-44. 
demais resistem identiticaçāo com qualquer língua conhecide.

Mas, tenha-se presente que tais singularidades näo eram privativas das inscriçōes mágicas.

Que tais singularidades sảo universais, ouçamos a Carlos Navarro y Lamarca a propósito dos indigenas da América: "Entre los americanos, tenian ciertas palabras un poder mágico y misterioso al que obedecian los espíritus. La maldición mataba como una maza. Cuando el hechicero indigena "concentraba ou medicina" I lanzaba un anatema vibrante, no había salvación para su enemigo. Las fórmulas mágicas, cantos, encantos y conjuros del ritual indigena, eran casi siempre una sucesión de palabras ó sflabas sin sentido alguno. Se suponía que los Dioses entendian lo que no alcanzaban los hombres" (23).

As vêzes as expressōes enigmáticas são o resultado de pronúncia ou escrita defeituosa. Numa fórmula para afugentar ratos - Spitium salutis Sgavidanis (24) - tôdas com terminaçōes latinas, enquanto se identifica a segunda dição, nada se sabe quanto à terceira (nome próprio talvez), e a primeira mal dará para cotejar com stipes, stipitis, "tronco, estaca, árvore" ou com stips, stipis, "moeda; proveito, lucro". Enquanto se proferem essas palavras, rega-se a casa com infusão de rosas e um jasmim.

Para não ser picado pelas pulgas, deve-se dizer ock seis vêzes seguidas (25). A palavra parece um eco do alemão dialetal vloch, "pulga", ou do inglês bug, "percevejo", como que, com o seu nome, se esconjurasse o impertinente ou o nojento inseto (26).

(23) "Compendlo de le Fistorts General de Americs". B. Alres, 1910, D. 173.

(26) J. W. Scott, "Tratedo de Mrgit Ocults". p. 68.

(25) Idem, Ibldem, p. 60.

(20) Lela - o curloso extudo etimológlco do percevefo por Leo 8pitzer em "Anales del Iastituto de Lingllistica", Unj. de Cuyo, Mendoça, 192., t. I, D. 38 e segs.

Tals sevandijas so conslderados seres demaniacas, como comprova o ingl. bor que, primitiramente, slgniflcava "espectro" (cf. Irlandes 
Num livro português, de 1833, que condena as superstiçöes, registra-se que o dizer três vêzes onasages cura o mal dos dentes, e que proferir - sista, pista, rista, xista - evita o mal da gôta (27). Como esta, é curioso notar que muitas fórmulas são rimadas: "Os curandeiros benzedores usam ensalmos de palavras desconexas, com rimas consoantes (de balanço e manso, postila • Santa Camila)..." (28).

A propósito da colocação das palavras, convém lembrar a antiqüuissima poesia sacra, o "Carmen Arvale", datada de 218 d.C., gravada em mármore, descoberta em Roma, no Vaticano. E o protocolo dos doze irmãos arvais, sacerdotes de Ceres, instítuídos pelo primeiro rei de Roma. Nela há perfeita identidade entre o número de sílabas e o número das palavras, de correspondência horizontal e vertical, de aliteraçăo, de assonância, de igualdade de forma e de fundo (29). El-la (30):

\section{Enos Lases Invate \\ [E] nos Iances Iurate \\ Enos Lases luvato}

bacan, "fantasma"), e, para a sua ellminaça, proferem-se esconjuracóes, nas vesperas de dias festlvos e princlpalmente da Pliscoa.

Afirma Spitzer que., certamente, por causa do sentido de Belseba, "senhor das moscas". Goethe, no "Fausto", faz Mefistofeles chamar-se a sl próprio, alén de FHegengott,

"Der Herr der Ratten und der Mruse,

Der Fliegen, Frö6che, Wanzen, Lause" (I, v. 1518).

(27) "Rev. Lus.", v. 20, 1817, p. 272.

(28) Luls Chaves, "A Grei Portuguesa" In "Rev, Lus"., v. 28, 1930, p. 75.

(28) Jean Cousin, "trolution et Structure de lo Langue Latine", Paris, 194,, p. 147.

(30) Segundo A. Ernout, "Recuell de Textes Latins Archalques", Paris, 1938, p. 107. Aste $A$. declara que o texto fol multo corrompldo, renovado, desflsurado por várlos defeitos, o que lhe dificulta a interpretaḉón. Contudo apresenta algumas observaghes: Enos = nos? ou enom, "tum? Lacen = Larea; neve lue rwo = neve luom ruem; ruem = rulasm? Marmar = Marmor, forma redobrada de Marn; ins incarrere $=$ dn da ourrere?, 1.6 , aln, Imperativo de sino? th pleores $=$ in plaree? ler $=\nabla \infty$. de ferus? fo corradical de tal, ete? Bemunals = Bemones?, dirindado das sementes; conctos = cunctus? ou "quisque"? triumpo = expbale de exclamaço triunfal. 


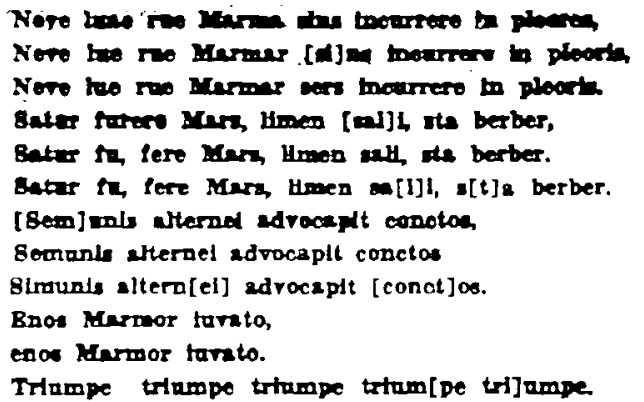

Apesar das apuradas investigaçōes, tem êste canto resistido a qualquer traduçăo. Tal se explica pela natureza do assunto. Trata-se de oraçāo de caráter esotérico, misterioso, cuja composição, embora proferida conscientemente, em tempos ulteriores já não mais se apreendia o sentido das suas palavras, pelo menos em parte. A oração tinha eficácia mais pelo ato de proferi-la do que pelo seu significado. A sua linguagem, é sabido, não condiz com a das inscriçōes ou textos da mesma época. Também se pode admitir a hipótese de haverem propositadamente mal desfigurado as palavras ou a sua colocaçāo, etc., uma vez que a oraçĩo era gravada, e, pelo quê, mais ou menos exposta a olhares profanos, embora colocada em recinto privado (31).

E possivel que, ao lado de expressões correntes, enxertas-

Foran propostas dirersas traduçes. Ernout achs quo "tout cecl eat tro aventurours".

Cesar Cantu no v. III da "Fintórla Unjversal", trad. de Antonio harDes, apresenta esta traduclo: "Nos, Lares, Juvate! Ne luem, ruem lou rutnam), Mamera. saas incurrero in plures! Satur esto, lere Mars! In lmen trall! 8ts! Verbers (llmea?) - Bemones alternl, adrocste cunotus! NOs, Samere. Juvato! Tripudia!"

(31) Ja na ma's afastads anuruldade se procedia a ocultaça de pictograPlas ao olhares profanos: "Les pelntures de nos cavernes sont parfols situes dans des recotns ou sur des anfractuosités de rochers peu accessbles: on a supposé qu'elles ont été traces dans ces endrolts parco qu'elies aurslext fte Laterdites (Lbous) aux femmes, aux onfants of. d'une manlère gépérale, aux non-Inities" (Jacques de Morgan, "L'Humenle Préblatarique", Parlos, 1924, p. 246). 
sem deliberadamente outras, dialetais, justamente para encobrir ou semi-encobrir o peasamento.

Propositada obscuridade possuem os gatás do Avesta, afirma Meillet: "Se os gatás do Avesta sáo mais que ininteligiveis, é que os autores os fizeram deliberadamente de modo que as combinaçōes de palavras não foram naturais... Os hinos védicos e a cançāo dos irmãos arvais de Roma também sāo obscuros adrede..." (32).

O caso é que, frequientemente, em tôdas as latitudes, em tôdas as coletividades primitivas, suas oraçōes e seus cantos mágicos, se não foram compostos em linguagem esotérica, vieram a ficar assim, intraduziveis, pelo tradicionalismo supersticioso.

Em vista de as palavras sagradas nos rituais deverem não ser modificadas e, sim, repetidas integralmente ou sempre de um mesmo modo, às vêzes até nas mínimas particularidades, porque, para êles, a eficácia dessas rezas ou invocaçōes dependem justamente dessa observância tradicional, aconteceu que, através dos séculos, suas palavras, não seguindo a evolução das demais nos usos profanos, permaneceram estáveis a ponto de serem ininteligiveis às novas gerações(33).

Em trabalho de campo que realizei entre os indigenas caingangues de Palmas, Paraná, registrei uma oração aos mortos e uma cantiga para dança, cujas letras säo intraduzíveis. Apenas uma que outra palavra pode ser entendida (34). Antes de mim, com os mesmos silvícolas, o prof. Herbert Baldus (35) recolheu, sem que o informante pudesse traduzir, uma oraçāo destinada aos falecidos e um canto de dança para a festa dos mortos (36).

(32) Cltado por O. Jespersen, "Humanldad, Nac16n, Indivduo", p. 238-287.

(39) Com respelto aos Romanos e aos Gregos, จ. Fustel de Coulanges, "A Cldade Antiga", v. I, 2." ed., 1920, p. 208-287 e nota 1.

(34) R. F. Mansur Guérlo6, "Estudas sobre a Lingua Caingangue" in "Arquiros do Museu Paranaense", v. II, Curitiba, 1942, D. 152-153, B, na separata, p. 58-59.

(95) Herbert Baldus, "Sprachproben des Kaingang von Palmas", sep. de "Anthropos", $t:$ 33, 1935, p. 203.

(36) Para se ter ldéla de como usamos arcásmo em oraçōes, lembremos, om port., padre (= "pal") na reza dominleal padre-nomo o nas lo- 
Karl Bücher, citado por Jespersen (37), estudando a origem da poesia, menciona os ilheus de Andamá que sacrificam ao ritmo as palavras da prosa, mudando-a ou abreviando-as de tal modo que quase pode dizer-se têm uma especial linguagen pó́ticn, e é de opiniāo que o ritmo das cançōes dos povos primittro nho era regido pela linguagem, mas, sim, pelo ritmo do trabalho de que se ocupavam, enquanto cantavam. E cada classe de trabalho tem um compasso e este é o que determina o ritmo da cançáo acompanhante (38).

A nảo observância à letra poderá acarretar desgraças, mesmo em assunto nāo religioso.

P. ex., os echantis, africanos da costa ocidental, têm cantores protissionals que narram, em melodias especiais, os grandes feitos de seus reis, mas evitam o perigo de mutilar-lhe ou corromper-lhe cada palavra, cada frase, porque, admitido o trovador na casta, desde então é punido de morte pelo menor êrro ou no texto ou na notação (39).

cuçbes Padre Etemo, Eteroo Padro, Santo Padre, e madre (= "mse") em Santa Madre Igreja.

Os protestantes evitam a expressåo padre. cersmente porque designa, na linguageon corrente, o sacerdote catolico. Bubstituem-na por pal

- "Pal nosso que estás nos céus...", que, afinal, é tamberm empregada pelos católicos.

(37) "Humanldad, Nación. Indivlduo", p. 240 e 241.

(38) Esta explicactio se eproxims do clamar concomitena hipotese da orlgem da linguagem, "d'après laquelle la parole serait nee des cris qul, chez les primitifs, accompagnent tout travall en commun" (A. Bricteux, "Esal sur l'Orlgine du Langage". Seralag, s/d, p. 10).

(39) Marcel Jourse, "Etudes de Psychologie Inroulstique", Parts, 1925, p. 169. Na resta dúplda que, em tal condjças, flca intscta a linguagem. Havls passado. diz o A., mais de 800 anon sem que essa narracto apresentasse modiflcaçál "Clsro es, iala a propósito Jespersen, claro es que las mutaclones del lenguaje se sustroen on gran medida a la vigliancla humana y por esta razón ocurse que, sln que los natipos so den cuenta, su lenguaje se va modiflcando poco a poco con el uso diarlo y su transmision a las nuevas generaciones. Pero en el grado que pueden, tratan Hgurosamente de que nada camble (salvo los casos en que la creencia en el poder mistico del nombre exige la adopción de nuevas palabras\}, mantenléndose la vigilapcia mas escrupulose para que no se produzca alteración alguna en las formas sagradas del culto religioso 
A propósito das exteriorizaçōes símiles dos indígenas americanos, afirma Carlos Navarro y Lamarca: "Algunos cantos no tenían letra. En otros era esencialísimo el pronunciar exactamente las palabras consagradas. Cualquier equivocación al respecto, destruía, según el indio, el mágico conjuro, y podia producir consecuencias funestas. Ell canto era, en fin, un vehículo para llegar a los seres invisibles" (40).

Vimos que rezas, fórmulas mágicas, poesias religiosas, etc., obedecem a determinada colocação das palavras, mas há outras cujo número de sílabas e de vocábulos, aliteração e assonlncia såo outros tantos requisitos formais. Acrescente-se ainda que, como se disse, a rima desempenha papel importante, como neste exemplo de Varrão: Terra pestem teneto, salus hic maneto! (41).

E entre os romanos muitas fórmulas de juramento, de invocação, de oração, eram expressadas por frases de três membros (trikôlon), provàvelmente por se atribuir poder mágico à trindade (42). Há exemplos no "carmen arvale".

A entoação era outra exigência, talvez indispensável. A propósito de um trecho de uma das epístolas de Horácio (I, 34-35) - "Sunt verba et voces quibus hunc lenire dolorem

Possis et magnam morbi deponere partem" - Leite de Vasconcelos chama a atenção para verba, que "significa "ensalmo" ou "fórmula mágica", e voces [que] designa o tom musical da recitação". (43).

y los himnos ceremoniales. A este vigilante culdado sobre los sonidos tradicionales de las viejas palabras se debo que los antiguos htmon vedicas de la Indla hayan aldo conservado con tal fldelidad que $00-$ nocemos sus formas y su pronunciación hasta el detalle más pequefio". (O. Jespersen, "Humanidad, Naclón, Individuo", p. 283).

(40) "Compendio de la Historia Genersl de America", p. 147.

(41) J. Cousin, "tvolution et structure de lo Langue Latte", p. 14.

(12) Idem, Ibldem, D. 156-157.

(4\$) "Miscelanea" in "Rev. Lus.", 20, 1917, p. 165. Otta af notas de duas edlgóes de Horáclo, asdm como o "Corpus Inscriptionum Latinarum"; Marquardt. "Le Cuite cher les Romoins"; O Helm. "Incantaments Marica Graeca Latina", Lipsia, 1902. 
Como as fórmulas mágicas eram freqüentemente ritmadas, tinham o nome de carmina. Cl. carmen arvale.

A importância da magia através do canto é denunciada pe. los tèrmos canere (44), excantare, incantare, incantatio, incan. tamentum, praecinare, occinare (entre os romanos).

Como o vates, "adivinhador, profeta", manifestava os oráculos (vaticinia) através de ritmos, passou vates a significar "poeta" (45). O verbo correspondente é vaticinari.

No port. sāo continuadores com idéias de magia - encantar e encantamento, vaticinar e vaticínio.

Também entre of celtas, o canto servia para fins mágicos (46).

Por outro lado, os poetas da antiga Irlanda se confundiam com os magos, cujas sátiras, chamadas também encantamentos, eram tremendas maldiçōes - tôda uma regiāo poderia ficar estéril por um ano; faziam aparecer chagas que desfiguravam as vítimas, levando-as ao desespêro; chegava-se até a causar- lhes a morte. Nem os animais escapavam (47). Nas guerras, o concurso de muitos poetas satíricos multiplicava o efeito dos seus encantamentos para dar a vitória aos seus patrícios.

A rivalidade entre os bardos muitas vêzes se resolvia com um debate, luta de poder entre mágicos.

Eram todos temidos; náo resta dúvida. E mais de uma vez

(4) "C'est un terme de la langue augurale et maglque, dont les formules sont des meloptes rythmées" (Ernout e Meillet, "Dict. Ltym. de La Langue Lat.", s.v. cano). Ver A. J. Fernandes de Carralho, "Diclonurlo das Institulobes, Usos e Costumes dos Romanos", Braga, 1804, p. 174.

(45) Id., lb., s.v. untes.

(46) "Lorsque deux arme étalnt sur lo polnt d'engager in batalle, Il ar-

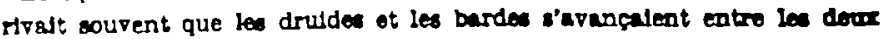
armées, et. par le magie de leurs chants, leur talsatent tomber les armes des malns" (Georges Dottin, "Les Iltteratures Coltiques". Parls, 1924, D. 128).

(67) "Longtemps encore, les bardes Irlandals gardkreat is rtputation do detrulre par leurs tncantations les rats e les ouris". (Id., ib., p. 148). 
o reis da Irianda tentaram bani-los, por cause do seu número (48), indisciplina e exigências.

Pelo que se vê, para os homens, principalmente os primitivos, há conex̧̉o intima, quase ou mesmo mágica, entre a palavra e a coisa por ela designada. A palavra nāo é sinal cómodo para denotar objeto, ato ou fato, porém é a sua mesma substáncia, a sua própria alma, e, portanto, imutável.

Não é, pois, de admirar que conhecer as coisas pelo nome é tê-las em seu poder e tê-las em poder é dar-lhes um destino bom ou mau. I se elas tiverem virtudes maléficas, ou benéficas, neutralizar-se-lhes-āo, ou aproveitar-se-lhes-ão os efeitos.

- "O febre, exconjuravam os curandeiros do Atharda-Veda, tu não me escaparás; eu te conheço pelo nome!"

Até entre os civilizados, conhecer o nome de' uma doença, esta parece dominada a meio. Há doentes que se sugestionam pelas palavras inusitadas, dificeis, que tais são os têrmos técnicos proferidos pelo médico, os quais comportam certa precisão, inobservada nos têrmos comuns, correntes. Entre as crianças observa-se fato análogo. Não ficaräo satisfeitas, enquanto não souberem o nome das coisas: "El niño considera los nombres como realidades objetivas ligadas misteriosamente a los cosas y en cierta manera esenciales a ellas. Un objeto sin nombre es para el niño algo incompleto, casi inexistente, imaginario" e "la tendencia infantil es "materializar" el nombre; esto es, considerarlo como parte de la cosa real misma en lugar de como algo extraño y arbitrariamente enlazado a ella" (49).

Até aqui tratamos superficialmente das palavras que podem ou devem ser proferidas. Há, no entretanto, palavras que não podem ou não devem ser proferidas e às quais reservamos o próximo trabalho - são os tabus lingüísticos (50).

(48) No tempo do rel Maelcobs, de Oister, contaram-s0 1.200 magoc-satirlstas (Id., ib., p. 143).

(40) Citaço em O. Jespersen. "Humanidad, Nactón. Individuo", p. 215.

(50) Em 1961, publlcamos uma breviesima visto - "Tabus Lingalisticos" no vol. I dos "Arqulvos do Museu Paranaense" (p. 148 a 160). 


\section{N D I C E}

Pth.

"LETRAS" - Homero Batiste de Barros . . . . . 3

GENEROS POETICOS - Temistocles Linhares . . 5

PAPINI - Luis Castagnola . . . . . . . . . 28

INTRODUÇAO AO ESTUDO DO SIMBOLISMO -

Wilson Martins . . . . . . . . . . . . 42

ANGEIL GABRIEL - Guillermo de la Cruz-Coronado . 66

ZUR DEUTSCH-BRASIIANISCHEN MISCHSPRACHE

- Reinhold Bossmann . . . . . . . . . . 96

DA SOLEDAD CASTELHANA A SAUDADE PORTU-

GUESA - Silveira Bueno . . . . . . . . 115

MORFOLOGIA DO VERBO TUPI - Arion Dalligne

Rodrigues . . . . . . . . . . . . . 121

PROPOSITAL E PROPOSITALMMNTÉ - José de Śa

Nunes . . . . . . . . . . . . . . 153

A MAGLA DA PALAVRA - R. F. Mansur Guérios . . 168

UM INQUERITO LINGUTSTICO POR DENTRO -

Orvaldo Pinheiro dos Reis. . . . . . . . 183

NOTAS DE BIBLIOGRAFLA E DE CRITICA . . . 180

NOTICIARIO . . . . . . . . . . . . . 198 